\title{
Viewpoint
}

DOI: $10.1057 /$ palgrave/jors/2601304

\section{A comment on 'A new method for joint replenishment problems' by Fung and Ma}

Fung and $\mathrm{Ma}^{1}$ proposed two algorithms for determining the optimal policy for the joint replenishment inventory problems. They conducted numerical experiments on randomly generated problems to demonstrate that their algorithms outperform the existing algorithms for almost all of the test problems.

Whenever a number of items are jointly replenished, a major set-up cost, which is independent of the number of items ordered, is involved and a minor setup cost is incurred for each individual item on order. The objective is to minimize the total relevant cost per unit of time of the system. The procedure for determining the optimal policy for items jointly replenished was first described in Goyal. ${ }^{2}$ The procedure required determining the lower bound and the upper bound of the basic cycle time and then evaluating all alternative policies within the bounds and selecting the policy with lowest total relevant cost. The resulting inventory policy required that each major setup is undertaken at equal time intervals as well as the minor setup cost for each item is undertaken at equal time intervals. Fung and $\mathrm{Ma}^{1}$ identified such a policy as Goyall in their paper.

Andres and Emmons ${ }^{3}$ in their note on Goyal ${ }^{2}$ showed with the help of a two-item example that it may not be economical to incur each major setup cost at equal time intervals. However, in their example the major setup cost was only $2 \%$ of the minor setup cost for individual items. Hence, it is not surprising that Goyall provided a suboptimal policy. In the extreme case when the major setup cost is almost zero, then it may indeed be more economical to order each item individually.

Van Eijis, ${ }^{4}$ in response to the observation made by Andres and Emmons, suggested a still lower bound as compared to the one suggested by Goyal. ${ }^{2}$ Fung and $\mathrm{Ma}^{1}$ found the algorithm based on the bounds proposed by Van Eijis ${ }^{4}$ computationally expensive.
Fung and $\mathrm{Ma}^{1}$ describe Goyal2 as the algorithm having lower bound which is $(1 / \sqrt{ } 2)$ of the lower bound as given in Goyal1. In their experimentation Fung and $\mathrm{Ma}^{1}$ give results for the algorithm suggested by Viswanathan ${ }^{5}$ as well as the algorithms described by them as Imp. 1 and Imp. 2 .

It seems that Goyal, ${ }^{6}$ which described a simple procedure for tightening the bounds, as given in Goyal, ${ }^{2}$ escaped the attention of Fung and $\mathrm{Ma}^{1}$ and others. If the procedure given in Goyal ${ }^{6}$ is used to obtain to obtain the lower bound and the upper bound of the basic cycle time for the example given Goyal, ${ }^{2}$ then one needs to evaluate only 9 intervals for Goyal1 and 25 intervals for Goyal2. As per Table 1 of Fung and $\mathrm{Ma}^{1}$ the number of intervals considered by them is 20 and 42 for Goyal1 and Goyal2 respectively.

Although personally I found the algorithms of Fung and $\mathrm{Ma}^{1}$ interesting. I suspect that I will find it difficult to teach them even to my well intentioned and highly motivated graduate students. I leave it to the readers to draw their own conclusions.

\section{References}

1 Fung RYK and Ma X (2001). A new method for joint replenishment procedures. J Opl Res Soc 52: 358-362.

2 Goyal SK (1974). Determination of optimum packing frequency of items jointly replenished. Mngt Sci 21: 436-443.

3 Andres FM and Emmons H (1976). On the optimal packaging frequency of products jointly replenished. Mngt Sci 22: 11651166.

4 Van Eijis MJG (1993). A note on the joint replenishment problem under constant demand. J Opl Res Soc 44: 185-191.

5 Viswanathan S (1996). A new optimal algorithm for the joint replenishment problem. J Opl Res Soc 47: 936-944.

6 Goyal SK (1975). Note on: determination of optimum packaging frequency of items jointly replenished. Mngt Sci 22: 386.

Concordia University, Canada

SK Goyal 